\title{
4
}

\section{Student Perspectives on Teaching and the Prevent Policy}

\section{Alex Elwick, Lee Jerome, and Hans Svennevig}

\begin{abstract}
In this chapter we shift our focus away from adults enacting policy to consider how young people think schools can help them to develop their knowledge and understanding of terrorism and extremism. The evidence suggests that young people generally support the values of democracy and reject the use of political violence, but they want their teachers to develop critical media and political literacy and trust them to explore multiple perspectives. Our review of government-endorsed educational resources concludes that they fall short of what young people want and often represent simplistic and uncritical counter-narratives. We argue that a genuinely educational approach will take more heed of young people's opinions and engage in a more critical exploration of the issues.
\end{abstract}

\author{
A. Elwick • H. Svennevig \\ UCL Institute of Education, London, UK \\ e-mail: a.elwick@ucl.ac.uk; h.svennevig@ucl.ac.uk \\ L. Jerome $(\bowtie)$ \\ Department of Education, Middlesex University, London, UK \\ e-mail: 1.jerome@mdx.ac.uk


Keywords Prevent Duty • Countering Violent Extremism • Student perspectives $\bullet$ Teaching material

\section{Introduction}

Research in relation to Prevent in education has tended, as with much education policy research, to focus on the ways in which the policy is interpreted and enacted, primarily by teachers. In this chapter we focus on what we know about young people's views and experiences (see also Chap. 8). One of the most obvious ways in which young people have been affected by the Prevent Duty is through referrals to the Channel programme and approximately half of all referrals to date have been young people up to the age of 20, including several hundred primary school children (see Chap. 1 for more details). There is also a second strand of activity which is more explicit about promoting a positive set of ideas and values that run counter to extremist narratives. Department for Education (DfE) policy states that 'schools and childcare providers can also build pupils' resilience to radicalisation by promoting fundamental British values and enabling them to challenge extremist views' (DfE, 2015, p. 5). The same DfE guidance has a whole section on building children's resilience towards radicalisation which notes that:

Schools can build pupils' resilience to radicalisation by providing a safe environment for debating controversial issues and helping them to understand how they can influence and participate in decision-making. Schools are already expected to promote the spiritual, moral, social and cultural [SMSC] development of pupils and, within this, fundamental British values. (DfE, 2015, p. 8)

This link between SMSC education, fundamental British values (FBVs) and Prevent is further emphasised in Home Office guidance (2019), which highlights that 'all publicly-funded schools in England are required by law to teach a broad and balanced curriculum which promotes the spiritual, moral, cultural, mental and physical development of pupils' (Home Office, 2019). 
As the rest of this volume illustrates, the Prevent policy tends to reduce young people's agency, almost inevitably framing them as vulnerable and in need of protection (see Chap. 7 for a discussion of how age has an impact on this). However, it is also important to remind ourselves that children and young people exercise their own agency in the education system. Most obviously they can choose to engage positively, or challenge and reject aspects of what schools attempt to teach them. More subtly, they bring their own life experiences, identities, preconceptions and concerns to school, and experience the curriculum through those individual perspectives. A complete picture of policy enactment will address not just how high-level policy is translated into practice by professionals, but also how the policy is experienced by the young people who are the object of the policy.

This chapter exemplifies how useful it can be to adopt a student perspective by focusing initially on the issue of what students want to learn about terrorism, extremism and Prevent. Once we have outlined the answer, we move on to consider the extent to which the educational resources endorsed by the government provide the kind of education young people want in relation to these issues. We show there is a mismatch between what students want and what the government directs teachers towards, and we start to explore some of the implications of this tension for teachers.

\section{What Do Students Want to Learn?}

In the first part of this chapter we draw on an evaluation conducted by Jerome and Elwick (2016, 2019a) of a project run by the Association for Citizenship Teaching (ACT) with ten secondary schools. ${ }^{1}$ The data includes questionnaires from 232 secondary students and 10 student focus groups. Citizenship teachers in each school planned and taught a unit of work related to Prevent, covering an aspect of terrorism or extremism that they thought would be of relevance and interest to their students. The evaluators invited students to reflect on the lessons they had experienced, and also addressed some more general questions about their knowledge and attitudes. In addition we draw on several other relevant 
studies, which have started to investigate the Prevent Duty from students' perspectives. Quartermaine (2016) conducted research in six schools, which included 264 student questionnaires and group discussions with 73 students, and Lockley-Scott (2016) conducted similar work in three case study schools. In addition Green (2017) conducted three focus groups with Muslim teenagers, which included some discussion of their experiences of school and college. We have also identified one relevant secondary study in which Janmaat (2018) re-analysed existing data from 420 young people for evidence of their knowledge of, and support for, the FBVs. Given that there are over 12 million people below the age of 18 in the UK, we cannot claim to provide a reliable overview of the situation for all children and young people, especially given the small research base on which we are able to draw. However, the findings from these projects illustrate how useful it is to consider young people's views and the data below identifies some insights into how young people feel Prevent should be implemented in the education system.

It is worth making one obvious observation at the outset - that all young people currently in school were born after the $9 / 11$ terrorist attacks in the USA, and for most of them 'terrorism' is generally associated with Islam. This connection is almost inevitable given the dominant media and policy framing of Islamist extremism, and the promotion of Britishness and British values in various guises as a form of antidote to extremism or radicalisation (Revell \& Bryan, 2018). Nevertheless, students in our research routinely told us that they had few opportunities to discuss terrorism, extremism or the media portrayal of these issues, either in school or at home (Jerome \& Elwick, 2016). Those we spoke to often argued that not only did they want opportunities to learn about the facts, but they also need to be guided by teachers they trust to develop a deeper understanding of what is happening and how to make sense of it. As we listened to the focus groups we developed a strong sense that the students themselves felt that better knowledge and understanding would help them to build some form of resilience-especially against the fear and confusion that often accompanied high-profile terrorist attacks.

Terrorists want us to be scared ... and we just can't be scared of it, so we need to talk about it more. 
Here they tell you the facts and the truth ... not protecting us ... they let us know what these people actually do. (Students quoted in Jerome $\&$ Elwick, 2016)

In the following sections, we consider some of the data about what students feel about terrorism, extremism and the FBVs, and explore what the students think would be useful to them in building their understanding.

\section{Young People Are Already Very Supportive of the FBVs and Less Likely to Support Political Violence Than Adults}

When teachers enact Prevent in the curriculum, this is often framed by the requirement to promote the FBVs (as the other chapters in this volume confirm). In this section we argue that listening to students provides several reasons why this might be both unnecessary and counterproductive.

Within the Prevent policy the FBVs are seen as one way in which schools can promote resilience, as those who agree with the FBVs are likely to reject extremist ideologies. Janmaat (2018) has undertaken a secondary analysis of survey data collected from school students before the introduction of the FBV guidance and Prevent Duty and reports that there were already near universal levels of support for the values listed as FBVs. He combined a number of survey items related to young people's level of support for democracy, the rule of law and toleration (now bundled together in policy as the FBVs) in order to construct what he describes as a measure of 'support for FBVs'. This measure refers to students' attitudes towards the concepts, not to the Prevent policy itself. Janmaat reports that levels of support for FBVs among young people are already very high (97.5\% of the respondents scored higher than the neutral mid-point of 3 on his 1-5 FBV scale [p. 260]) and do not differ between the white British majority and various minority ethnic groups (p. 251).

There is also some evidence to suggest that young people are particularly sceptical about whether acts of political violence can ever be justified. In the ACT evaluation research (Jerome \& Elwick, 2016) the 
questionnaires included some questions to explore whether political violence could be justified for a variety of causes (such as religion, the environment, animal rights). These questions were based on an opinion poll conducted in 2011 and discussed in Sobolewska (2012), to enable a comparison between the student sample and the general population. As Sobolewska indicates in her discussion of the opinion poll data, younger respondents tended to be less likely to suggest any justification for terrorism could be legitimate, and our findings reflect this. For example, when asked if terrorism could be justified on the grounds of environmental causes, animal rights or protecting one's faith, only $6-8 \%$ thought it could ever be justified (this includes 'strongly agree' and 'agree' options on a 5-point scale, with the mid-point being 'uncertain'). In the opinion poll this was $8-9 \%$ when respondents drawn from the general population were given a straightforward yes/no/don't know option, but $13-15 \%$ when they were allowed to offer a 'qualified yes'. Over half the opinion poll respondents thought terrorism could be justified if it was part of a fight against foreign occupation or an oppressive government, but only $8-13 \%$ of students agreed. The large difference between the students and the general population in the final two questions may well indicate a lack of understanding of how contextual factors may influence judgements about the use of violence, an interpretation supported by the observation that more students opted for 'uncertain' in the last two questions.

Given these two observations, one might reasonably conclude that there is no particular reason to believe that all young people need a specific FBV intervention - on the face of it they are almost unanimously supportive of the concepts now described as FBVs and less likely to support violence than the general population. One might criticise this aspect of policy for being unnecessary, but perhaps no more than that. However, the qualitative data from other studies (e.g. Green, 2017) has indicated that some students experience the specific framing of democracy, the rule of law and tolerance as being 'fundamentally British' in particularly problematic ways, and this raises the possibility that rather than being merely redundant, it may have unintended negative effects. 


\section{Some Muslim Students Experience FBV as Discriminatory, Exclusionary and Intimidating}

Islamophobia in schools has been the subject of much debate that predates the introduction of the Prevent Duty (see, e.g. Van Driel, 2004). Against this background, it is perhaps unsurprising that Lockley-Scott (2016) noted that Muslim students do not always feel school is a 'safe place' because of negative labelling and stereotyping-both from students and sometimes from staff. Several of her female respondents reported they felt they were being closely observed and treated in 'a bad way'. For example,

[School] is not always a safe place as ignorant people will associate you with Isis. My headscarf makes society view me as a terrorist.

I think people are intimidated because I wear a headscarf. (Students quoted in Lockley-Scott, 2016, p. 6)

Lockley-Scott also notes that Muslim students sometimes reported an anxiety about 'who's listening', leading to self-censorship. These findings suggest that Muslim students may find the discussion of terrorism and the FBVs particularly uncomfortable.

This conclusion is supported by Green's focus groups with Muslim teenagers in Tower Hamlets, London, who reported feeling discrimination, being spied on and experiencing pressure to secularise. One group who attended the same sixth form cited the example of a school talk by the Quilliam Foundation, which they interpreted as implying, 'if you're not a Quilliam Muslim, you're an extreme Muslim' (Green, 2017, p. 247). For a majority of these young people, despite the fact that they identified as British, greatly valued democracy and embraced the principle of toleration, they felt their Britishness was often not recognised by others and that they were marginalised. One of Green's participants argued:

I don't think British culture and Islam contradict so much, but I think that they want us to change so much that we're no longer following Islam, we're just following British culture. (Focus group participant from Green, 2017, p. 248) 
This sentiment implies that the conflation of FBVs and Britishness, and the sustained critique of multiculturalism (Vincent, 2019) are making themselves felt in particularly harmful ways for some young Muslims.

\section{Young People Want to Learn About Terrorism and Extremism to Build Their Religious, Political and Critical Media Literacy}

Given the commonplace connection between Islam and terrorism in the media and social attitudes (Matthes, Schmuck, \& von Sikorski, 2019), it is not surprising that Quartermaine found 'there is a genuine interest from pupils in discussing the relationship between terrorism and religion' (2016, p. 25). When they were given the opportunity to engage in such discussions, students were indeed grateful for the opportunity to critically explore the relationship between religion and terrorism. In particular, one of the consistent findings from the evaluation of the ACT project (Jerome \& Elwick, 2016) related to the way that students came to perceive the role of the media in reinforcing the idea that there is a relationship between Islam and terrorism:

It's strange to think that maybe the way the media represents these people completely changes the opinion of a person. They might have been fine with a certain person before and then after they've read something about the person or their religion and it completely changes the way they see people ... (Student quoted in Jerome \& Elwick, 2016)

The teachers in the ACT project generally made sure that students were introduced to several different examples of terrorism, such as the IRA or anti-apartheid activists, in order to expand their understanding beyond Islamist terrorism. Having learned about other forms of terrorism and political violence, several students noted that 'the media only really talks about Muslim terrorists, they brush over other forms of terrorism'. For some they were then able to think about how this influenced their own views, both about terrorism and about Islam. 
I don't know because the media is so powerful I think we're all just brainwashed and we're all stuck in that mentality that we should be scared of them [Muslims]. (Student quoted in Jerome \& Elwick, 2019a)

This raises the prospect that the right kind of critical educational engagement with Prevent and the FBVs may also provide students with the resources to question and intervene in the unconscious perpetuation of islamophobia. $^{2}$

Here there are clear indications of the kind of knowledge that is helpful to expand students' understanding of the relevant issues. For example, having studied media representations, one student commented:

The word Islamophobia is quite interesting because you hear about all the racism that goes on in the world and it kind of sums it up ... I like giving it a name, you can identify it more. (Student quoted in Jerome \& Elwick, 2019a)

Quartermaine's students said they wanted opportunities to consider the ideological views of the 9/11 bombers, and those students who studied the motivations of terrorists as part of the ACT project confirmed that this was valuable and that they were capable of engaging with the openended nature of such an investigation. This questions assumptions from some quarters that young people need to be protected from extremist ideology.

The whole project is to make the students aware of what protests are like for different people and to understand the full story because when you go home the media don't give you the full story ... teachers don't want you to believe that - they want you to get the full story. (Student quoted in Jerome \& Elwick, 2019a)

Students often referred to this idea that they wanted to move beyond partial media representations and to get the 'whole story' including the views of those involved in terrorism. In this way students felt that teachers were best placed to help them move beyond the superficial knowledge they gain through media and social media: 
Before I didn't know, I knew what was going on the news, but I didn't know how to understand it.

Lessons help you understand why they're doing it ... sometimes when you hear things on the news you think 'why are they doing that?' (Students quoted in Jerome \& Elwick, 2019a)

If schools do not offer this kind of educational approach, it is difficult to imagine where else young people might get such an education.

Some students demonstrated that there was a level of basic knowledge that they would not gain if it was not covered in lessons. In one school with high levels of English Defence League (EDL) activity in the community, one group of Muslim boys speculated that the 'far right' might be a group of people who were very supportive of rights, demonstrating that it is dangerous to assume young people learn about such issues through informal means. A similar point was made in a focus group:

Before we were learning about this I didn't really know what an extremist group was, I never heard about the neo-Nazis or things like that, but when we started learning about it I started like not only knowing what the groups were and what they did but also two points, like I didn't know you could have a different opinion, I thought they would all just be the same ... (Student quoted in Jerome \& Elwick, 2019a)

Several students in our focus groups went beyond the personal factors often discussed in relation to radicalisation to consider how such processes are shaped by political context and lived experience. For example, some students speculated on how a person's attitudes towards groups such as ISIS might be shaped by how they perceive the West's bombing and other foreign policy interventions in majority Muslim countries, or how they might experience Britain's democracy if they felt marginalised, discriminated against and disempowered.

Obviously a group like ISIS didn't start from nothing, obviously there's something there to help it start and help it build ... there's a purpose to it and something has made them do it.

I think the main thing that is the most difficult thing to find out about this topic is why the extremist groups ... obviously they have their reasons 
and their beliefs ... I think that's the hardest thing to find out and I don't know if you'll ever get the answer to it. (Student quoted in Jerome \& Elwick, 2019a)

In these considerations students demonstrated an ability to apply political empathy and consider how similar situations could be interpreted by others, and to consider how those drawn to terrorism might justify their own actions and perceive their own agency. In doing so they in fact reflect some of the academic critique of simplistic and over-individualised accounts of how people come to engage in or support political violence (Coolsaet, 2016).

The first part of this chapter provides some useful insights into secondary students' perspectives on the Prevent Duty. First, it suggests that young people are sympathetic to the concepts included in the FBV framework, but the framing of the ideas as 'fundamental' and 'British' may be unnecessary (they are supported anyway) and possibly counterproductive. Second, it indicates that young people want opportunities to learn about terrorism, the motivations of terrorists and the different forms of terrorism. Third, they also value opportunities to learn about how the media represents terrorism and the relationship between this and their own perceptions of who constitutes a threat. And finally, we would argue that these responses indicate young people have the capacity to live with a level of uncertainty - they want to be better informed about terrorism as a political phenomenon, but they do not expect to find easy answers or simple explanations.

\section{What Do Government-Endorsed Educational Resources Offer Students?}

Having reflected in the previous section on what the evidence to date tells us about student views related to the Prevent Duty, in this section we examine the educational resources that have been developed and promoted by the government, and consider to what extent they meet the challenges outlined above. 
We explore resources suggested for teachers in the Educate Against Hate (EAH) website (https://educateagainsthate.com), which has been developed by the Department for Education and the Home Office 'to provide practical advice, support and resources to protect children from extremism and radicalisation'. Methodologically, we follow Ford's (2019) analysis of how textbooks discuss terrorism and extremism, which employs a flexible approach to discourse analysis, reading materials to explore the 'themes, labels, subjectivities and imagery deployed' (Ford, 2019 , p. 5). In practical terms this means looking at the ways in which key concepts are defined and employed, what examples are given, who is represented and what narratives are constructed. Our primary objective was to examine the materials promoted by the government to consider how they interpreted the Prevent Duty, the balance they struck between safeguarding and the FBVs, and the extent to which they engaged with the kinds of issues highlighted by the students themselves (as discussed above).

At the time of writing the DfE was reviewing the website, with the possibility that a considerable re-design or replacement project may be implemented. However, as of January 2020 the Teachers Classroom Resource section of the website included references to 40 resources. In deciding which of these to focus on for our review, we went through several screening processes. First, we excluded any links to generic websites or resources which were not explicitly related to the Prevent Duty, the DfE guidance or FBVs, and which failed to refer to terrorism, extremism or radicalisation. One example of such material is UNICEF's Rights Respecting Schools Award which, despite being a popular resource for promoting children's rights, does not relate explicitly to the rationale, aims or themes of the EAH website, nor the Prevent/FBV context. A second stage of screening consisted in testing the web-links, where projects were held on other websites, this resulted in several more exclusions where there were no live links to follow or where users had to register personal details with a third party organisation to get access to material. This left 26 resources for further investigation. Based on the titles and introductory pages for each we identified which resources explicitly addressed the following criteria: 
- Links to the citizenship curriculum

- Links to other subjects such as Religious Education (RE) or Personal, Social and Health Education (PSHE)

- Critical thinking

- Political literacy

- Media literacy

- Active citizenship/student voice

- Safeguarding

We then selected five resources ${ }^{3}$ which met four or more of these criteria. This was intended to enable us to focus on those resources most likely to provide comprehensive coverage to enable a fair evaluation of the content. These resources are summarised in Table 4.1.

The sample we have selected represents a rather open and inclusive approach to the production of resources. Some schools and colleges have been involved, some community groups with potentially relevant expertise have contributed resources (e.g. organisations with expertise in working with young people or tackling islamophobia), and victim perspectives are also represented. In reviewing this selection of resources, we seek to illustrate how the Prevent Duty is being enacted within these documents

Table 4.1 Resources selected for review from Educate Against Hate website

\begin{tabular}{ll}
\hline Resource & Brief description \\
\hline $\begin{array}{l}\text { (1) Think. Protect. } \\
\text { Connect. }\end{array}$ & $\begin{array}{c}6 \text { lessons, a teacher and student pack for youth settings, } \\
\text { schools and post 16 colleges and for people on the } \\
\text { Autistic Spectrum produced by East Sussex Safer } \\
\text { Communities Partnership }\end{array}$ \\
$\begin{array}{c}\text { (2) No Love for } \\
\text { Hate }\end{array}$ & $\begin{array}{c}\text { A series of lessons aimed at 14-19-year-olds and produced } \\
\text { by Harlow College and Luton Sixth Form Colleges, in } \\
\text { partnership with the Home Office }\end{array}$ \\
$\begin{array}{c}\text { (3) Democracy } \\
\text { Challenge }\end{array}$ & $\begin{array}{c}\text { A programme of creative activities broadly targeted at } \\
\text { with the Cabinet Office }\end{array}$ \\
(4) Getting on & Two lessons and their resources produced by the Welsh \\
Together & Getting on Together project to counter Islamophobia \\
(Secondary) & Miriam Hyman was killed in the London Bombings, 2005, \\
(5) Miriam's Vision & and this resource is produced by the Miriam Hyman \\
& Memorial Trust. Lessons are aimed at 11-14-year-olds \\
\hline
\end{tabular}


and thus how these contributors have already re-framed the Prevent Duty from their own perspectives (Lundie, 2017, p. 16). We cannot comment on how teachers might select, adapt or interpret such materials in practice (see Chap. 8), and so here we offer some questions that might be useful for teachers encountering these resources.

\section{Where Do These Resources Come from? Who Produced Them and Why?}

Lundie (2017) has noted that the Prevent Duty provided the stimulus for a new group of experts to emerge, often from backgrounds other than education. Such experts emerge as policy entrepreneurs or champions (Ball, Maguire, \& Braun, 2012), as the policy opens up new career prospects and new opportunities to advocate for their interpretation of the policy. Whilst the uniform style of the website tends to obscure these issues of provenance, our review demonstrated that the resources reflect the particular expertise or backgrounds of the organisation that produced them. For example, Miriam's Vision was produced by a trust established by her family; unsurprisingly, therefore, this resource tends to focus on the victims of terrorism, rather than on understanding the nature of terrorism itself. By contrast the Getting on Together resources emerge from a long-term ongoing project in Wales to counteract Islamophobia in the wake of the $9 / 11$ bombings. This therefore tends to focus on presenting positive messages about Islam. No Love for Hate is produced by two further education (FE) colleges in Prevent Priority Areas and is largely focused on right-wing extremism in these local areas.

Whilst each of these resources therefore takes a distinctive approach, this reflects the nature, purpose and interests of the groups producing them. One issue that is relevant here is that the organisations rarely have expertise in the issues being discussed, for example, UK Youth produced the Democracy Challenge, but its expertise is in youth associations rather than democracy. Similarly, No Love for Hate is produced by staff and students at the FE colleges, but no contributors are identified as having expertise in Countering Violent Extremism (CVE) or right-wing extremism. This may well be a contributory factor in the issues we discuss below. 


\section{What Is the Purpose of These Resources? Do They Promote Critical Thinking or Passive Acceptance of a Simplified Narrative?}

The FBVs are presented in policy as something to be 'promoted' whereas the young people discussed above are clear that they want opportunities for critical, open-ended discussion. Teachers have to make their own judgement about the extent to which they are happy to promote the FBVs as some kind of antidote to the 'fixed, rigid and dogmatic' views espoused by extremists (LGFL, 2015), as opposed to using them as a starting point for deeper exploration. Some of the resources simply imported government definitions of the FBVs and the definition of extremism as 'opposition' to them (see, e.g. Think, Protect, Connect). Similarly, No Love for Hate featured an on-line quiz that included the following question:

Question. What do you think the British values project is all about? Answer 1. It means displaying the Union Jack.

Answer 2. Showing fair play and stiff upper lip.

Answer 3. Speaking English and eating fish and chips.

Answer 4. Showing tolerance/respect for different faiths and beliefs.

At times the resources slipped from discussing (or promoting) the FBVs into narrow cultural representations of Britishness, such as Big Ben, the Queen, fish and chips (Think, Protect, Connect). Another approach was adopted by Democracy Challenge, which simply describes and advocates for a rather narrow (formal, Westminster-centred) version of British democracy. Similarly, the citizenship lessons in Miriam's Vision largely avoid issues related to terrorism in favour of exploring the range of campaigning strategies available to people protesting against the third runway at Heathrow. These examples position the teacher as an uncritical promoter of pre-determined answers and fail to provide students with the opportunities they wanted to discuss and explore the FBVs and terrorism.

In contrast to these positive presentations of the FBVs, No Love for Hate is more explicit in attacking the basis of far-right extremist belief. In 
this project there is a Prezi on-line presentation which plays along to Beethoven's 7th Symphony. This shows the rise of European fascism as a result of the Wall Street Crash, featuring graphic pictures of dying children and prison camp inmates, and then argues the rise of far-right extremism in the USA and Europe today is a parallel political phenomenon. There is no learning activity, simply some facts and information aligned into a single and simplistic narrative. The shocking images, stirring sound-track and single simplistic narrative/perspective actually illustrate the very propaganda methods students are warned against in a previous lesson on far-right social media strategies.

Taken together these examples indicate that counter-narratives within these resources tend to be fairly simplistic and lack criticality or nuanced engagement with a range of perspectives. This stood out as one of the key requests of young people in our research-they trusted teachers to tell them the truth and introduce them to multiple perspectives. Whilst teachers are among the most trusted professionals in young people's lives (Ipsos MORI, 2018), it seems to us that such trust might be squandered if teachers use it to promote simplified and simplistic thinking, where students want critical and open thinking. The promotion of ideas such as democracy, liberty and toleration in the abstract also fails to induct young people into the kinds of difficult 'turbulent' discussions that are essential in democracy (Davies, 2014).

\section{Who Is Represented in the Resources and How Are They Represented?}

It is not surprising that sometimes teachers reproduce some of the dominant social tropes evident in mainstream discourse around terrorism and extremism (see Chap. 3). To some extent one could argue that for a teacher to engage in preventing something, they have to imagine some sort of threat or problem, and there is some evidence that teachers come to perceive (elements of) the communities they serve as the problem to be solved (Jerome \& Elwick, 2019b).

Some of the most obvious examples of unconscious bias are evident in the material produced by teachers-perhaps reflecting the fact that they may lack expertise in the area, lack professional editing services or may 
have had less time to spend on such projects. It may also reflect the fact that they are imagining their resources being used and interpreted in their particular context, responding to their perception of the problem. In Think, Protect, Connect, for example, all but two of the examples of extremism relate to Islamism and are all related to individuals, rather than groups or movements, but the two examples of the far-right are both linked to images of flags not individuals. In this way pre-existing stereotypes of what terrorists look like are likely to be reinforced-perhaps this is even more serious given this resource claims to be particularly suitable for students with autism, who the authors describe as 'more likely to take things literally' (p. 5 of the teacher toolkit). By contrast, No Love for Hate is almost exclusively concerned with far-right extremism and portrays such people as directly comparable to Nazis. A quiz includes this question:

Question. What do you think of a white boy saying, 'I don't feel I belong here. I'm the odd one out'.

Answer 1. It sounds like he lives in his own little world.

Answer 2. He probably said it because he is feeling alone.

Answer 3. Get over it, No love for hate.

Answer 4. Perhaps he doesn't understand the terror families run from.

None of these responses acknowledge the boy's perceptions, and as Busher's (2015) research into the EDL has shown, such sentiments are complex but very real among people who endorse such organisations. These approaches seem to fail to provide space to consider the different perspectives of people and how their views develop, which students in our research said they wanted. In their place there are sometimes rather stereotypical or caricatured images of people identified as extremist.

\section{Do These Resources Engage Directly with the Problem of Terrorism and Extremism, or Do They Skirt Around the Issues?}

As noted above, some resources, such as Democracy Challenge, are framed on the EAH website as linked to the FBVs, but in reality they do not engage with the broader debates about the nature of democracy or 
the threats to it. Others which appear as though they will tackle the Prevent agenda more directly often seem to skirt around the core issues of terrorism, extremism and the dilemmas that arise. Getting on Together includes some distinctive elements; for example, it represents a range of positive voices about Islam (to counteract negative images in mainstream culture) and it suggests that there are different types of extremism. We supplemented our review by looking at the primary lesson on extremism, to assess how the authors explored this issue, and here the story of Rosa Parks is presented for discussion, presumably as an example of positive extremism. As is all too typical, the Rosa Parks story is invoked as an individual story of bravery, rather than as a collective story of political action (Schmitz, 2015), but here it seems compounded by the suggestion that it might also be considered an example of extremism.

The citizenship lessons in Miriam's Vision similarly hint at a topic that appears to be at the core of the Prevent agenda, but then veer away. These lessons start with a focus on the Human Rights Act and prompt students to think about what level of surveillance is compatible with our right to privacy. These opening activities encourage students to consider how rights must be balanced, but the lessons then move on to consider how one can achieve non-violent change (through the case study of the third runway at Heathrow) and therefore fail to explore the big issue hinted at initially. A third example is evident in the Democracy Challenge where teachers are urged to engage in 'hot potato' debates, such as around immigration, but there are no resources or guidance to help with this (beyond logistical advice around putting students into groups, handing out sticky notes, etc.), and no clear objective about the purpose of such a discussion.

\section{Conclusion}

The data considered in this chapter indicate that young people are generally supportive of the FBVs but that the translation of them into the curriculum may lead to new problems of marginalisation or 'othering'. This is not to imply that an educational response is not potentially helpful, and we have outlined some of the ways that students feel schools could help them develop their understanding. Their requests seem fairly 
obvious - they want to build their understanding of terrorism and extremism so they can develop a better understanding of what is happening around them, and in this they find specific information valuable, such as different types of terrorism, the perspectives of those involved, and the way the media and social media operates in relation to recruitment and reporting. Yet the materials on offer to teachers to help them address this demand largely fall short. In the second part of this chapter, we have demonstrated that some of the resources risk reproducing negative or simplistic ideas that are evident in popular cultural tropes around terrorism and extremism. Starting with a focus on young people leads us to be concerned that the Prevent Duty may well be contributing to problems with the policy rather than equipping young people with the capacity to make sense of the post-9/11 world in which they live.

\section{Notes}

1. The authors would like to acknowledge the financial support of ACT for this evaluation, and the Home Office for funding of the overall project.

2. Since we collected this data there has been more media coverage of the extreme right, so it is possible that these perceptions may have altered somewhat.

3. This filtering process also identified 'The Deliberative Classroom' project (a collaboration between ACT, Middlesex University and the EnglishSpeaking Union) but, as the authors of this chapter were very involved with this project, we decided to omit it from this analysis to avoid a conflict of interest.

\section{References}

Ball, S., Maguire, M., \& Braun, A. (2012). How schools do policy: Policy enactments in secondary schools. Abingdon, UK: Routledge.

Busher, J. (2015). The making of anti-Muslim protest: Grassroots activism in the English Defence League. Abingdon, UK: Routledge.

Coolsaet, R. (2016). 'All radicalisation is local': The genesis and drawbacks of an elusive concept. Brussels, Belgium: The Egmont Institute. 
Davies, L. (2014). Interrupting extremism by creating educative turbulence. Curriculum Inquiry, 44(4), 450-468.

DfE. (2015). The use of social media for online radicalisation. Retrieved from www.gov.uk/government/publications/the-use-of-social-media-foronline-radicalisation

Ford, K. (2019). This violence good, that violence bad: Normative and statecentric discourses in British school textbooks. Critical Studies on Terrorism, 12(4), 693-714.

Green, F. (2017). British values and identity among young British Muslims in Tower Hamlets: Understandings and connections. Journal of Children's Services, 12(4), 239-256.

Home Office. (2019). Revised Prevent Duty guidance: For England and Wales. Retrieved from www.gov.uk/government/publications/prevent-duty-guidance/revised-prevent-duty-guidance-for-england-and-wales

Ipsos MORI. (2018). Veracity index 2018. Retrieved from www.ipsos.com/ ipsos-mori/en-uk/advertising-execs-rank-below-politicians-britains-leasttrusted-profession

Janmaat, J. (2018). Educational influences on young people's support for fundamental British values. British Educational Research Journal, 44(2), 251-273.

Jerome, L., \& Elwick, A. (2016). Evaluation report on the ACT building resilience project. London: Association for Citizenship Teaching.

Jerome, L., \& Elwick, A. (2019a). 2019a). Identifying an educational response to the Prevent policy. British Journal of Educational Studies, 67(1), 97-114.

Jerome, L., \& Elwick, A. (2019b). Teaching about terrorism, extremism and radicalisation: Some implications for controversial issues pedagogy. Oxford Review of Education., 46, 222. https://doi.org/10.1080/0305498 5.2019.1667318

Lockley-Scott, A. (2016, November 26). What is the impact of UK government strategies preventing non-violent extremism on Muslim pupils in school? Paper presented at the University of Birmingham Education Conference.

London Grid for Learning (LGFL). (2015). What is the role of values in countering extremism? (Film). Retrieved from http://counterextremism.lgfl.org.uk/ videos/FR/HD/vid_vcn_1.mp4

Lundie, D. (2017). Security, safeguarding and the curriculum: Recommendations for effective multi-agency Prevent work in schools. Retrieved from http://cepa. hope.ac.uk/safetysecuritycurriculum 
Matthes, J., Schmuck, D., \& von Sikorski, C. (2019). Terror, terror everywhere? How terrorism news shape support for anti-Muslim policies as a function of perceived threat severity and controllability. Political Psychology, 40(5), 935-951. Quartermaine, A. (2016). Discussing terrorism: A pupil-inspired guide to UK counter-terrorism policy implementation in religious education classrooms in England. British Journal of Religious Education, 38(1), 13-29.

Revell, L., \& Bryan, H. (2018). Fundamental British values in education: Radicalisation, national identity and Britishness. Bingley, UK: Emerald Publishing.

Schmitz, P. (2015, January 28). How change happens: The real story of Mrs. Rosa Parks \& The Montgomery Bus Boycott. Huffpost. Retrieved from www. huffpost.com/entry/how-change-happens-the-re_b_6237544

Sobolewska, M. (2012). Measuring support for terrorism: A survey experiment and an attempt at a comparison. Paper presented at the Elections, Public Opinion and Parties conference, Oxford, September.

Van Driel, B. (Ed.). (2004). Confronting Islamophobia in educational practice. Trentham, UK: Stoke on Trent.

Vincent, C. (2019). Tea and the queen? Fundamental British values, schools and citizenship. Bristol, UK: Policy Press.

Open Access This chapter is licensed under the terms of the Creative Commons Attribution 4.0 International License (http://creativecommons.org/licenses/ by/4.0/), which permits use, sharing, adaptation, distribution and reproduction in any medium or format, as long as you give appropriate credit to the original author(s) and the source, provide a link to the Creative Commons licence and indicate if changes were made.

The images or other third party material in this chapter are included in the chapter's Creative Commons licence, unless indicated otherwise in a credit line to the material. If material is not included in the chapter's Creative Commons licence and your intended use is not permitted by statutory regulation or exceeds the permitted use, you will need to obtain permission directly from the copyright holder.

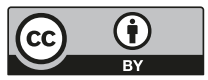

